\title{
Penerapan Jaringan Saraf Tiruan Dalam Memprediksi Gizi Balita Pada Puskesmas Siantar Utara Kota Pematangsiantar
}

\author{
Daniel Arbanus Simbolon ${ }^{1}$, Dedy Hartama ${ }^{2}$, Fitri Anggraini ${ }^{3}$ \\ ${ }^{1,2,3}$ Program Studi Teknik Informatika, STIKOM Tunas Bangsa, Pematangsiantar \\ Jln. Sudirman Blok A No. 1, 2 dan 3 Pematangsiantar, Sumatera Utara - INDONESIA \\ ${ }^{1}$ danielassimbolon@gmail.com, 2 dedyhartama@amiktunasbangsa.ac.id, \\ 3tranggraini850@gmail.com
}

\begin{abstract}
The North Siantar Health Center's Puskesmas is a health sector engaged in public health sciences, at the Office of the North Siantar Sub-District of Pematangsiantar City conducted research with the Nutritional research variables under five months of age. attacked by various diseases ranging from external diseases and internal diseases. Artificial Neural Network is a method of grouping and separating data whose working principle is the same as Human Neural Networks, this Science processes systems and structures so that they become information.
\end{abstract}

Keywords: Artificial Neural Network (ANN), Backpropagation, Detection, Toddler Body Mass Index

\begin{abstract}
Abstrak
Puskesmas Siantar Utara adalah suatu bidang kesehatan yang bergerak pada ilmu kesehatan masyarakat, penelitian ini bertujuan untuk mempermudah dalam memprediksi Indeks Massa Tubuh (IMT) pada gizi balita dikarenakan usia balita sangat mudah diserang berbagai penyakit mulai penyakit luar dan penyakit dalam. Jaringan Saraf Tiruan merupakan suatu metode pengelompokan dan pemisahan data yang prinsip kerjanya sama seperti Jaringan Saraf Manusia, Ilmu ini memproses sistem dan beberapa struktur sehingga menjadi sebuah informasi.
\end{abstract}

Kata Kunci: Jaringan Saraf Tiruan (JST), Backpropagation,Prediksi, Indeks Massa Tubuh Balita

\section{Pendahuluan}

Gizi merupakan komponen kimia yang terdapat dalam zat makanan yang sangat dibutuhkan oleh tubuh untuk perkembangan dan pertumbuhan serta memiliki hubungan dengan kualitas sumber daya manusia[1]. Status gizi adalah ukuran keberhasilan dalam pemenuhan nutrisi untuk anak yang diindifikasikan oleh berat badan dan tinggi badan anak. Status gizi juga didefinisikan sebagai status kesehatan [2]. Anak dibawah usia lima tahun (Balita) sangat mudah terserang berbagai masalah kesehatan dan gizi, permasalahan gizi anak balita berbeda dengan gizi orang dewasa. Pelayanan kesehatan umumnya menggunakan parameter berat badan menurut umur dimana terdapat kekurangan fasilitas yang dapat mengakibatkan interpretasi status gizi yang dapat membuat banyak orang keliru bila terjadi masalah kesehatan, keadaan gizi dikatakan baik apabila keseimbangan dan keserasian antara perkembangan fisik dan perkembangan mental, telah banyak penelitian yang terjadi dibidang kesehatan salah satunya dengan cara memprediksi keseimbangan status gizi dengan Indeks Massa Tubuh (IMT) dari gizi balita pada bayi lima tahun kebawah (Balita) pada bidang kesehatan.

Pada perkembangan zaman teknologi sekarang jaringan saraf tiruan sudah sangat populer untuk dijadikan pembelajaran terutama pada bidang kesehatan dan teknologi [3]. Kelebihan jaringan saraf tiruan ini adalah tidak perlu adanya asumsi bahwa data harus berdistribusi multivariat normal. Pada beberapa tulisan disebutkan bahwa algoritma 
pembelajaran jaringan saraf tiruan menyelesaikan permasalahan model deret berkala nonlinier dengan algoritma pembelajaran backpropagation [4]. Dalam Jaringan Saraf Tiruan (JST) merupakan suatu sistem pemrosesan informasi yang mempunyai karakteristik menyerupai jaringan saraf biologi (JSB). Jaringan saraf tiruan tercipta sebagai suatu generalisasi model matematis dari pemahaman manusia (humancognition) yang didasarkan atas asumsi sebagai pemrosesan informasi terjadi pada elemen sederhana yang disebut neuron, sinyal mengalir diantara sel saraf atau neuron melalui suatu sambungan penghubung. Bobot ini akan digunakan untuk menggandakan atau mengalihkan sinyal yang dikirim melalui setiap sel saraf akan menerapkan fungsi aktivasi terhadap sinyal hasil penjumlahan berbobot yang masuk kepadanya untuk menentukan sinyal keluarannya [5]. Metode backpropagation adalah algoritma pembelajaran yang terawasi dan biasanya digunakan oleh perceptron dengan banyak lapisan untuk mengubah bobot - bobot yang terhubung dengan neuron - neuron yang ada pada lapisan tersembunyi [6]. Pada Puskesmas Siantar Utara Kota Pematangsiantar status gizi menjadi acuan perkembangan dan pertumbuhan anak umur yang dibawah lima tahun serta menjadi tolak ukur keseimbangan kesehatan, di Puskesmas Siantar Utara Kota Pematangsiantar jumlah anak yang terkena gizi kurang sekitar $11 \%$ anak sedangkan anak yang memiliki gizi baik $89 \%$. Disini dapat di simpulkan pada Puskesmas Siantar Utara Kota Pematangsiantar gizi pada balita yang kategorikan baik memadai tingkat persenannya.

\section{Metodologi Penelitian}

\subsection{Gizi Balita}

Gizi balita merupakan komponen kimia yang terdapat dalam zat makanan yang sangat dibutuhkan oleh tubuh untuk perkembangan dan pertumbuhan bayi limat tahun kebawah serta memiliki hubungan dengan kualitas sumber daya manusia. Status gizi dapat diartikan juga sebagai ukuran keberhasilan dalam pemenuhan nutrisi anak yang diindikasikan oleh berat badan dan tinggi badan anak [7].

\subsection{Jaringan Saraf Tiruan}

Jaringan saraf tiruan merupakan salah satu representasi buatan dari otak manusia yang selalu mencoba untuk mensimulasikan proses pembelajaran pada otak manusia tersebut. Istilah buatan disini digunakan karena jaringan saraf tiruan ini diimplementasikan dengan menggunakan program komputer yang mampu menyelesikan sejumlah proses perhitungan selama proses pembelajaran [8]. Pada ilmu jaringan saraf tiruan proses pelatihan algoritma/metode backpropagation didasarkan pada hubungan yang sederhana , yaitu jika keluaran memberikan hasil yang salah, maka penimbang (weight) dikoreksi supaya galatnya dapat diperkecil dan tanggapan JST selanjutnya diharapkan akan lebih mendekati nilai yang benar [9]

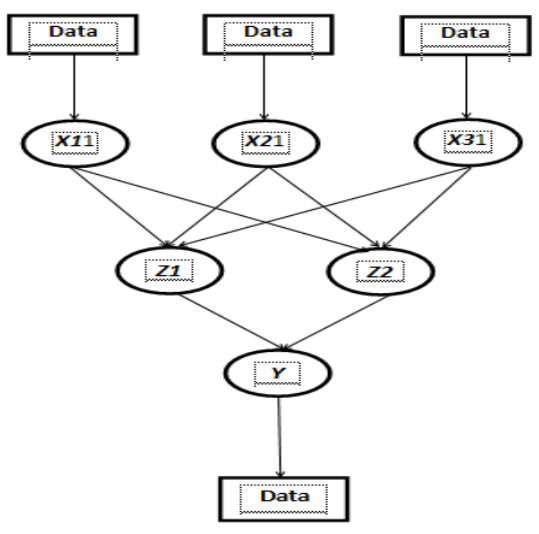

Gambar 1. Model Arsitektur Jaringan Saraf Tiruan 


\subsection{Algoritma Backpropagation}

Algoritma Backpropagation merupakan metode pelatihan yang terawasi (supervised) dan dirancang untuk operasi pada jaringan dengan banyak lapisan [10][11] Backpropagation merupakan algoritma pembelajaran yang biasanya digunakan oleh perceptron dengan banyak lapisan untuk mengubah bobot-bobot yang terhubung dengan neuron-neuron yang ada pada lapisan tersembunyi. Jaringan saraf tiruan backpropagation adalah metode yang paling mudah dipahami dan mempunyai konsep belajar yang sederhana dibandingkan metode-metode yang lain. Jarinagn saraf tiruan pertama kali diperkenalkan oleh Rumelhart, Hinton dan William pada tahun 1986, kemudian Rumelhart dan McClelland mengembangkannya metode ini pada tahun 1988 [13].

\section{Hasil dan Pembahasan}

\subsection{Normalisasi Data}

Dalam melakukan pelatihan dan pengujian, terlebih dahulu dilakukan normalisasi untuk mempermudah melakukan pelatihan dan pengujian data.

Formula normalisasi dapat dilihat pada persamaan berikut:

$$
x^{\prime}=\frac{0,8(x-a)}{b-a}+0,1
$$

Tabel 1. Data Training Tahun (2012-2014) Target 2015 Sebelum Di Normalisasi

\begin{tabular}{cccc}
\hline $\mathbf{2 0 1 2}$ & $\mathbf{2 0 1 3}$ & $\mathbf{2 0 1 4}$ & Target \\
\hline 13,25 & 19,64 & 25,77 & 22,40 \\
24,67 & 10,06 & 25,43 & 14,86 \\
18,55 & 19,75 & 20,35 & 15,60 \\
15,37 & 17,07 & 19,42 & 13,17 \\
18,49 & 17,07 & 14,85 & 12,42 \\
20,33 & 23,44 & 39,66 & 33,16 \\
\hline
\end{tabular}

Tabel 2. Data Training Setelah Di Normalisasi Tahun (2012-2014) Target 2015

\begin{tabular}{cccc}
\hline $\mathbf{2 0 1 2}$ & $\mathbf{2 0 1 3}$ & $\mathbf{2 0 1 4}$ & Target \\
\hline 0,18622 & 0,35892 & 0,52459 & 0,43351 \\
0,49486 & 0,10000 & 0,51541 & 0,22973 \\
0,32946 & 0,36189 & 0,37811 & 0,24973 \\
0,24351 & 0,28946 & 0,35297 & 0,18405 \\
0,32784 & 0,28946 & 0,22946 & 0,16378 \\
0,37757 & 0,46162 & 0,90000 & 0,72432 \\
\hline
\end{tabular}

Tabel 3. Data Testing Tahun (2015-2017) Target 2018 Sebelum Di Normalisasi

\begin{tabular}{cccc}
\hline $\mathbf{2 0 1 5}$ & $\mathbf{2 0 1 6}$ & $\mathbf{2 0 1 7}$ & Target \\
\hline 22,40 & 17,29 & 18,55 & 38,06 \\
14,86 & 20,41 & 24,09 & 29,56 \\
15,60 & 16,80 & 16,90 & 33,65 \\
13,17 & 13,44 & 19,55 & 39,05 \\
12,42 & 14,86 & 20,66 & 31,11 \\
33,16 & 30,77 & 39,08 & 41,15 \\
\hline
\end{tabular}

Tabel 4. Data Testing Setelah Di Normalisasi Tahun (2015-2017) Target 2018

\begin{tabular}{cccc}
\hline $\mathbf{2 0 1 5}$ & $\mathbf{2 0 1 6}$ & $\mathbf{2 0 1 7}$ & Target \\
\hline 0,37790 & 0,23561 & 0,27069 & 0,81396 \\
0,16794 & 0,32249 & 0,42496 & 0,57727 \\
0,18855 & 0,22196 & 0,22475 & 0,69116 \\
0,12088 & 0,12840 & 0,29854 & 0,84152 \\
0,10000 & 0,16794 & 0,32945 & 0,62043 \\
0,67751 & 0,61096 & 0,84236 & 0,90000 \\
\hline
\end{tabular}




\subsection{Analis}

Tabel 5. Kode Program Menggunakan Matlab 2011b Dalam Backpropagation

\begin{tabular}{|c|c|}
\hline Kode Training & Kode Testing \\
\hline $\begin{array}{l}>>\text { net }=\text { newff(minmax }(P), \text { [hidden layer,output } \\
\text { layer], }\{\text { 'tansig','purelin'\},'traingd'); } \\
>>\text { net.IW\{1,1\}; } \\
>>\text { net.b }\{1\} ; \\
>>\text { net. } L W\{2,1\} ; \\
>>\text { net.b }\{2\} ; \\
>>\text { net.trainParam.epochs }=10000 ; \\
>>\text { net.trainParam.show }=1000 ; \\
>>\text { net.trainParam.lr }=0.01 ; \\
>>\text { net.trainParam.goal }=0.001 ; \\
>>\text { net.trainParam.Lr }=0.01 ; \\
>>\text { net.trainParam.show }=1000 ; \\
>>\text { net }=\operatorname{train}(\text { net, } P, T) \\
{[a, P f, \text { Af, }, \text { Perf] }=\operatorname{sim}(\text { net }, P,[],[], T)}\end{array}$ & $\begin{array}{l}>P P=[\text { input data pengujian] } \\
>>T T=[\text { output pengujian] } \\
{[a, P f, A f, e, P e r f]=\operatorname{sim}(\text { net }, P P,[],[], T T)}\end{array}$ \\
\hline
\end{tabular}

\subsection{Pelatihan Dan Pengujian Data}

Pada penelitian ini menggunakan 5 (lima) model arsitektur pelatihan dan pengujian data yakni 3-35-1, 3-37-1, 3-45-1, 3-50-1 dan 3-55-1. Pelatihan dan pengujian ke 5 arsitektur dapat dilihat sebagai berikut:

Tabel 6. Model Arsitektur Backpropagation

\begin{tabular}{ccccccc}
\hline No & Arsitektur & \multicolumn{3}{c}{ Training } & \multicolumn{2}{c}{ Testing } \\
\cline { 3 - 7 } & & Epoch & Waktu & MSE & MSE & Akurasi \\
\hline 1 & $3-35-1$ & 304 & $00: 06$ & 0,00098626 & 1,30100992 & $50 \%$ \\
2 & $3-37-1$ & 215 & $00: 05$ & 0,00099193 & 2,73424277 & $67 \%$ \\
3 & $3-45-1$ & 187 & $00: 04$ & 0,00097871 & 3,18068972 & $83 \%$ \\
4 & $3-50-1$ & 83 & $00: 03$ & 0,00095960 & 20,66548899 & $50 \%$ \\
5 & $3-55-1$ & 114 & $00: 03$ & 0,00098302 & 1,79981969 & $50 \%$ \\
\hline
\end{tabular}

Berdasarkan tingkat akurasi pengujian dan Pelatihan 5 model arsitektur maka dapat disimpulkan bahwa model arsitektur 3-45-1 dengan epoch sebesar 187 iterasi dalam waktu 00:04 menghasilakan tingkat akurasi terbesar yakni 83\% merupakan model arsitektur terbaik untuk digunakan dalam proses estimasi tahun berikutnya.

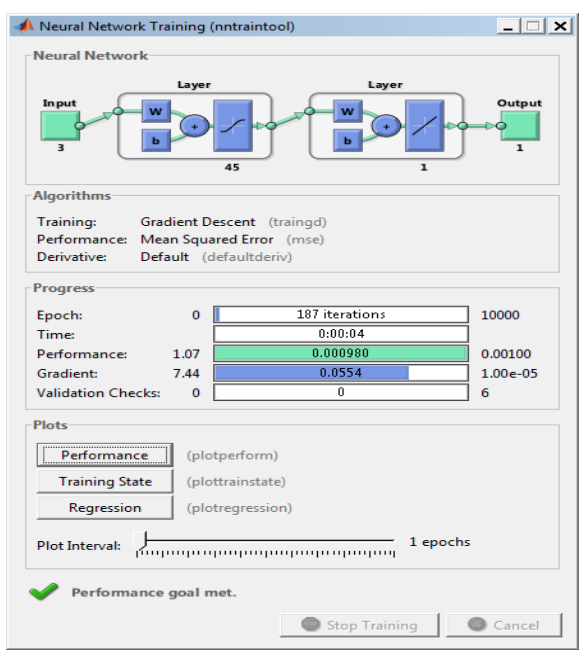

Gambar 2. Pelatihan Menggunakan Model Arsitektur 3-45-1 
Tabel 7. Hasil Akurasi Data Training Dengan Model Arsitektur 3-45-1

\begin{tabular}{cccccc}
\hline Pola & Target & Output & Error & SSE & Hasil \\
\hline Pola 1 & 0,43351 & 0,43280 & 0,00071 & 0,00000051 & 1 \\
Pola 2 & 0,22973 & 0,23450 & $-0,00477$ & 0,00002276 & 1 \\
Pola 3 & 0,24973 & 0,18980 & 0,05993 & 0,00359157 & 0 \\
Pola 4 & 0,18405 & 0,22650 & $-0,04245$ & 0,00180166 & 1 \\
Pola 5 & 0,16378 & 0,17890 & $-0,01512$ & 0,00022850 & 1 \\
Pola 6 & 0,72432 & 0,73940 & $-0,01508$ & 0,00022728 & 1 \\
\cline { 1 - 4 } & & Jumlah SSE & 0,00587227 & 83 \\
\cline { 1 - 3 } & & MSE & 0,00097871 & \\
\hline
\end{tabular}

Tabel 8. Hasil Akurasi Data Testing Dengan Model Arsitektur 3-45-1

\begin{tabular}{cccccc}
\hline Pola & Target & Output & Error & SSE & Hasil \\
\hline Pola 1 & 0,81396 & $-1,10910$ & 1,92306 & 1,23010281 & 0 \\
Pola 2 & 0,57727 & 1,02740 & $-0,45013$ & 1,05555076 & 1 \\
Pola 3 & 0,69116 & 0,74630 & $-0,05514$ & 0,55696369 & 1 \\
Pola 4 & 0,84152 & 3,45720 & $-2,61568$ & 11,95223184 & 1 \\
Pola 5 & 0,62043 & 1,82640 & $-1,20597$ & 3,33573696 & 1 \\
Pola 6 & 0,90000 & 0,97650 & $-0,07650$ & 0,95355225 & 1 \\
\cline { 1 - 4 } & & Jumlah SSE & 19,08413831 & 83 \\
\cline { 1 - 3 } & & MSE & 3,18068972 & \\
\hline
\end{tabular}

Tabel 9. Hasil Prediksi Gizi Balita 5 Tahun Kedepan Dari Tahun 2019- 2023

\begin{tabular}{|c|c|c|c|c|c|c|c|c|c|c|c|c|}
\hline \multirow[t]{2}{*}{ /Bulan } & \multicolumn{12}{|c|}{ INDEKS MASA TUBUH (IMT) } \\
\hline & 2012 & 2013 & 2014 & 2015 & 2016 & 2017 & 2018 & 2019 & 2020 & 2021 & 2022 & 2023 \\
\hline $0-6$ & 13,25 & 19,64 & 25,77 & 22,40 & 17,29 & 18,55 & 38,06 & 39,99 & 41,04 & 41,26 & 41,25 & 41,26 \\
\hline $0-12$ & 24,67 & 10,06 & 25,43 & 14,86 & 20,41 & 24,09 & 29,56 & 36,34 & 40,14 & 41,15 & 41,26 & 41,26 \\
\hline $0-24$ & 18,55 & 19,75 & 20,35 & 15,60 & 16,80 & 16,90 & 33,65 & 38,29 & 40,47 & 41,16 & 41,25 & 41,26 \\
\hline $0-36$ & 15,37 & 17,07 & 19,42 & 13,17 & 13,44 & 19,55 & 39,05 & 39,47 & 40,86 & 41,11 & 41,26 & 41,26 \\
\hline $0-48$ & 18,49 & 17,07 & 14,85 & 12,42 & 14,86 & 20,66 & 31,11 & 37,82 & 40,95 & 41,18 & 41,26 & 41,26 \\
\hline $0-60$ & 20,33 & 23,44 & 39,66 & 33,16 & 30,77 & 39,08 & 41,15 & 41,18 & 41,19 & 41,20 & 41,26 & 41,26 \\
\hline
\end{tabular}

\section{Kesimpulan}

Berdasarkan uraian yang telah di paparkan, penulis dapat menyimpulkan bahwa :

a. Hasil prediksi Indeks Massa Tubuh Balita mengalami peningkatan yang sangat baik dibanding dengan tahun- tahun sebelumnya, penilitian ini memberikan dampak baik dalam gizi balita.

b. Setelah dilakukan pelatihan dan pengujian data telah didapat hasil dari penelitian gizi balita yang dapat membantu pihak Puskesmas Siantar Utara Kota Pematangsiantar dalam melihat Indeks Massa Tubuh Balita setiap tahunnya, serta dapat membantu mengatasi gizi buruk pada balita seperti memberi asuapan gizi yang baik serta memberikan suntik imunisasi.

c. Dengan menggunakan model arsitektur tersebut adapun hasil prediksi Indeks Massa Tubuh Balita pada Puskesmas Siantar Utara Kota Pematangsiantar pada tahun 2019 ke tahun 2020 mengalami penaikan yang sangat tinggi dengan nilai rata-rata $83 \%$, seperti pada usia 0-6 bulan nilai Indeks Massa Tubuh pada Balita pada tahun 2019 yaitu 39,99 dan tahun selanjutnya 41,04 begitu juga pada pengelompokan usia balita lainnya sedangkan,

d. pada tahun 2020 sampai dengan tahun 2023 mengalami penaikan yang nilainya 45\% seperti pada usia 0-6 bulan pada tahun 2020 yaitu 41,04 dan tahun selanjutnya 41,26 begitu juga tahun lainnya.

Beberapa saran bagi peneliti selanjutnya:

a. Agar diadakan penelitian-penelitian lebih lanjut mengenai Indeks Massa Tubuh Balita terhadap gizi pada Puskesmas Siantar Utara Kota Pematangsiantar 
menggunakan metode pada Jaringan Saraf Tiruan misalnya metode Learning Vektor Quantization (LVQ), Perceptron.

b. Agar penelitian selanjutnya menggunakan 2 lapisan tersembunyi supaya penelitian dapat dikembangkan untuk mendapatkan hasil yang lebih optimal dengan waktu yang lebih singkat.

c. Pada penelitian selanjutnya agar mengkombinasikan metode-metode lainnya karena Arthificial Neural Network merupakan algoritma untuk menyelesaikan masalahmasalah non-linier, oleh karena itu untuk menangani masalah-masalah non-linier tersebut menggunakan Arthificial Neural Network ini, misalnya metode yang dapat dikombinasikan dengan Arthificial Neural Network yaitu Fuzzy Logic sehingga kekurangan-kekurangan yang terdapat pada ANN dapat diselesaikan oleh Fuzzy Logic, begitu juga dengan sebaliknya sehingga software yang dibangun akan semakin sempurna.

\section{Daftar Pustaka}

[1] Dar, M. H. (2017). Penerapan Metode Backpropagation Neural Network Untuk Memprediksi Produksi Air, 12, 203-208.

[2] Dulasrip, M. (2015). Penggunaan Jaringan Saraf Tiruan Untuk Mendeteksi Status Gizi balita Dengan Metode Backpropagation. skripsi.

[3] Fathina, H. (2015). Jaringan Syaraf Tiruan Untuk Klasifikasi Status Gizi Balita Jenis Kelamin Laki-laki Dengan Metode Backpropagation.

[4] Febrina, M., Arina, F., \& Ekawati, R. (2013). Peramalan Jumlah Permintaan Produksi Menggunakan Metode Jaringan Syaraf Tiruan ( JST ) Backpropagation, 1(2), 174-179.

[5] Hidayat, R. (2018). Perancangan Sistem Inventori Barang pada Toko Family Usaha Berbasis Web.

[6] Khusniyah, T. W. (2016). Prediksi Nilai Tukar Petani Menggunakan Jaringan Syaraf Tiruan Backpropagation, 3(1), 11-18.

[7] Kusumadewi, K. (2015). Analisis Jaringan Saraf Tiruan dengan Metode Backpropagation Untuk Mendeteksi Gangguan Psikologi.

[8] Lesnussa, Y. A., Latuconsina, S., \& Persulessy, E. R. (2015). Aplikasi Jaringan Saraf Tiruan Backpropagation untuk Memprediksi Prestasi Siswa SMA ( Studi kasus : Prediksi Prestasi Siswa SMAN 4 Ambon ), 11(2), 149-160.

[9] Nugraha, A. P. (2015). Aplikasi Sistem Pakar Untuk Mendiagnosa Penyakit Dalam Menggunakan Metode Forward Chaining Dan Certainty Faktor Berbasis Web ( Studi Kasus : Poliklinik PT Pos Indnesia Bandung ), 2(2), 3676-3683.

[10] Rsud, P., Ambon, M. H., Lesnussa, Y. A., Rahakbauw, D. L., \& Tehuayo, S. (2016). Aplikasi Jaringan Syaraf Tiruan Backpropagation Untuk Memprediksi Potensi Serangan Jantung, 117-122.

[11] Santosa, F. H., Bahri, S., \& Ibrahim, M. (2018). Pengembangan aplikasi project Simulasi Limit Fungsi Mengunakan Matlab, 1(2), 80-89.

[12] Tambunan, H. S. (2016). Pengenalan Pola HIV Dan AIDS Menggunakan Algoritma Kohonen Pada Jaringan Syaraf Tiruan Backpropagation, 65-69.

[13] Wanto, anjar. (2018). Jurnal Teknologi dan Sistem Informasi Optimasi Prediksi Dengan Algoritma Backpropagation Dan Conjugate Gradient Beale-Powell Restarts, 3(2017), 370-380.

[14] Wardhani, K. S. (2014). Pengembangan Sistem Informasi Kartu Menuju Sehat Sebagai Alternatif Pengelolaan Posyandu Secara Digital.

[15] Widiasari, I. R., \& Ismanto, E. (2017). Jaringan Syaraf Tiruan Algoritma Backpropagation Dalam Memprediksi Ketersediaan Komoditi Pangan Provinsi Riau, 18-19. 
[16] Windarto, A. P., Studi, P., \& Informasi, S. (2017). Implementasi JST Dalam Menentukan Kelayakan Nasabah Pinjaman KUR Pada Bank Mandiri Mikro Serbelawan Dengan Metode Backpropagation, (1), 12-23.

[17] Yanto, M., Defit, S., \& Nurcahyo, G. W. (2015). Memprediksi Jumlah Reservasi Kamar Hotel Dengan Metode Bacpropagation (Studi Kasus Hotel Grand Zuri Padang ), 2(1). 